\title{
Associations of Internet Use with Oral Hygiene Based on National Youth Risk Behavior Survey
}

\author{
Subin Park ${ }^{1}$ and Jung Hyun Lee ${ }^{2}$ \\ ${ }^{1}$ Department of Research Planning, Mental Health Research Institute, National Center for Mental Health, Seoul, Korea \\ ${ }^{2}$ Department of Psychiatry, National Center for Mental Health, Seoul, Korea
}

\begin{abstract}
Objectives: To investigate the association of problematic Internet use with oral health behaviors and oral health status in a nationally representative sample of Korean adolescents.

Methods: Data from the 2010 Korea Youth Risk Behavior Web-based Survey (73238 Korean adolescents; mean age $15.06 \pm 1.75$ years; age range, 12-18 years) were used. Problematic Internet use was measured using the Korean Internet Addiction Proneness Scale for Youth-Short Form. Self-report questionnaires were used to assess oral health behaviors and oral health status of adolescents.

Results: Problematic Internet users were less likely to brush their teeth frequently [adjusted odds ratio (AOR) $=0.59$; 95\% confidence interval $(\mathrm{CI})=0.56-0.63$ ] and at school after lunch $(\mathrm{AOR}=0.89 ; 95 \% \mathrm{CI}=0.83-0.94)$ as well as more likely to perceive their oral health to be poorer $(\mathrm{AOR}=1.63,95 \% \mathrm{CI}=1.54-1.72)$ and experience oral symptoms ( $\mathrm{AOR}=1.75,95 \% \mathrm{CI}=1.65-1.86)$ compared to usual Internet users.

Conclusion: The study results indicate that problematic Internet use may adversely affect the oral health of Korean adolescents. Thus, oral health screening and Internet-based education are needed for adolescents experiencing problematic Internet use.
\end{abstract}

Key Words: Oral health; Problematic Internet use; Adolescents; Korea.

Received: August 31, 2017 / Revision: October 7, 2017 / Accepted: October 25, 2017

Address for correspondence: Jung Hyun Lee, Department of Psychiatry, National Center for Mental Health, 127 Yongmasan-ro, Gwangjin-gu, Seoul 04933, Korea

Tel: +82-2-2204-0136, Fax: +82-2-2204-0280, E-mail: leejunghyun1@gmail.com

\section{INTRODUCTION}

Oral health is essential to general health and wellbeing. Oral health problem influences eating, talking and other psychosocial areas of life, ${ }^{1,}$ and it significantly diminishes the quality of life. ${ }^{2)}$ Certain medical conditions such as diabetes and HIV infection ${ }^{3)}$ and psychosocial factors such as socioeconomic status ${ }^{4)}$ and stress ${ }^{5}$ were found to be risk factors for poor oral health. Adolescence is an important period with regard to establishing a healthy life-style such as frequent toothbrushing and regular exercise. ${ }^{6,7)}$ A healthy lifestyle in adolescence is important for lifelong health., ${ }^{8,9)}$

Use of substances such as alcohol, tobacco, and other illicit drugs has been associated with adverse oral health behaviors and poor oral health in previous studies. ${ }^{10,11}$ Addicts who are physically and psychologically dependent on substances neglect their oral hygiene, physical health, and nutrition, which are related to oral health problems. ${ }^{12)}$ Similarly, addiction to the Internet and uncontrollable Internet use which in-

This is an Open Access article distributed under the terms of the Creative Commons Attribution Non-Commercial License (http://creativecommons.org/licenses/by-nc/4.0) which permits unrestricted non-commercial use, distribution, and reproduction in any medium, provided the original work is properly cited. terfere with one's daily life ${ }^{13)}$ may also have a negative impact on the oral health. Excessive or problematic Internet use has been associated with an unhealthy life-style such as a sedentary life style, skipping meals, sleeping late, irregular meals, junk food habits, and short duration of sleep in adolescence. ${ }^{714-16)}$ Internet use including internet gaming, use of social networking sites, and information retrieval is considered to be a major recreational activity in adolescence. Problematic internet use was reported to have a prevalence of $10-30 \%$ among Korean junior or senior high school students. ${ }^{17-19)}$ However, to the best of our knowledge, there is no study investigating the association between problematic Internet use and oral health status among adolescents.

Given the high prevalence of problematic Internet use in Korean adolescents ${ }^{17-19)}$ and lack of a previous study in this area, we investigated the association of problematic Internet use with oral health behaviors and oral health status in a nationally representative sample of Korean adolescents. We hypothesized that problematic Internet use may negatively affect oral health behaviors and oral health status in adolescents. 


\section{METHODS}

This study was based on the data from the 2010 Korea Youth Risk Behavior Web-based Survey (KYRBS). ${ }^{20)}$ A nationally representative sample of students attending middle and high schools was obtained by a stratified multistage cluster-sampling method for the survey. A total of 74980 students from 400 middle schools and 400 high schools were engaged in the survey and the response rate was $97.7 \%$. The final study participants included 73238 students. ${ }^{7)}$ As KYRBS did not collect any personal information, written informed consent was not obtained from students. This study was reviewed and approved by the Institutional Review Board of the National Center for Mental Health (No. 116271-2017-02_001).

\section{Measurements}

\section{Problematic Internet use}

Problematic internet use was assessed using the Korean Internet Addiction Proneness Scale for Youth-Short Form (KSscale), a 20-item self-report tool to screen for youth who are prone to problematic internet use, developed by the Korean National Information Society Agency. ${ }^{21)}$ Each item is rated on a 4-point Likert scale. Six sub-factors constitutes the KS-scale: 1) disturbance of adaptive functioning, 2) addictive automatic thought, 3) withdrawal, 4) virtual interpersonal relationship, 5) deviant behavior, and 6) tolerance. Problematic Internet use was defined by the presence of one of the following: a total score above 48; a disturbance of adaptive function score above 15; a withdrawal score above 10; or a tolerance score above 12 . $^{7)}$

\section{Oral health behaviors and status}

Daily toothbrushing frequency was assessed by asking the following question: "When did you brush your teeth yesterday?" Participants were asked to indicate the times they had brushed their teeth yesterday from a list of five times: 1) before or after breakfast, 2) before or after lunch, 3) before or after dinner, 4) immediately before bed, and 5) after a snack. Based on these responses, participants were then classified into the following 2 groups: i) participants who brush their teeth three or more times a day and ii) participants who brush their teeth twice a day or less. Toothbrushing at school after lunch was assessed by asking the following question: "How often did you brush your teeth at school after lunch during the last 7 days?" The response options were always (1), mostly (2), sometimes (3), and never (4). Based on these responses, participants were then classified into the following 2 groups: i) always or mostly and ii) sometimes or never. A visit to the dental clinic during the past 12 months was assessed by ask- ing the following question: "In the past 12 months, have you visited a dental clinic for oral examination or dental treatment?" The response option was "yes" or "no." Self-perceived oral health status was measured by asking the following question: "Usually, how do you think is your oral health such as tooth and gum health?" The response options were very healthy (1), healthy (2), fair (3), unhealthy (4), and very unhealthy (5). Based on these responses, the participants were then classified into the following 2 groups: i) fair to healthy $(1-3)$ and ii) unhealthy (4-5). The experience of oral disease symptoms was measured by asking the following question: "Have you ever experienced the following symptoms during the past 12 months?" 1) a chipped or broken tooth, 2) toothache while eating hot or cold food or drinks, 3) tooth ache or throbbing, 4) painful or bleeding gums, 5) throbbing pain in the tongue or inside the cheeks, and 6) bad breath. If participants responded "yes" to at least one of the items, they were classified into the "having oral symptoms" group.

\section{Covariates}

Respondents were asked to report socio-demographic variables including sex, school grade, and residential type (i.e., with family, with relatives, with friends, alone, or in a dormitory, and in a facility). Respondents were also asked whether they have ever used a cigarette, alcohol, and illicit drugs with the following questions: "Have you ever drunk more than one glass of alcohol?," "Have you ever smoked even a puff of a cigarette?" and "Have you ever used drugs that are often used nonmedically (e.g., gas, bond, stimulants, cannabids, amphetamine, marijuana, codein, neuroleptics) for mood elevation, hallucinatory experience, or excessive diet?" The response option was "yes" or "no." The degree of perceived stress was assessed by asking the following question, "Usually, how much stressed do you feel?," the response options were very little (1) little (2), average (3), much (4), and very much (5). Based on these responses, the participants were then classified into the following 3 groups: i) <average stress (1-2), ii) average stress (3), and iii) >average stress (4-5).

\section{Statistical analysis}

Considering that the KYRBS involved a complex sampling design, weighted values were applied using the survey-related procedure to SAS software version 9.4 (SAS Institute Inc., Cary, NC, USA) for all analyses. The rate of post-hoc weight readjustment was calculated as the sum of the weights of gender, types of schools, and grades would equal to the number of national middle and high school student population.

Socio-demographic characteristics, substance use, and perceived stress were compared between problematic Internet users and usual Internet users using a $\chi^{2}$-test. Odds ratios and 
95\% confidence intervals were calculated from logistic regression analyses using oral health behaviors and oral health status as the main outcome variables and problematic Internet use as the principal predictor, before and after adjusting for sex, grade, residential type, alcohol use, smoking, illicit drug use, and level of perceived stress. Statistical significance was defined as an alpha level $<0.05$.

\section{RESULTS}

Among 73238 respondents, $15.9 \%$ were classified as problematic Internet users. Table 1 shows group-specific socio-demographic characteristics and health-risk behaviors. Problematic Internet users were less likely to live with their family (94.4\% vs. $95.7 \%$ ), and more likely to be males (69.6\% vs. $49.7 \%$ ), to use alcohol (59.6\% vs. $53.9 \%)$, cigarette (34.7\% vs. $24.4 \%)$, and illicit drugs (1.7\% vs. $0.5 \%)$, and to perceive much stress (55.1\% vs. $41.7 \%$ ), compared to usual Internet users.
Table 2 shows the results of binary logistic regression analysis. Univariate analysis revealed a negative association between problematic Internet use and frequent toothbrushing and a positive association between problematic Internet use and poor oral health and oral symptoms. Even after adjusting for socio-demographic characteristics and health-risk behaviors (variables in Table 1), problematic Internet users were less likely to brush their teeth frequently [adjusted odds ratio $(\mathrm{AOR})=0.59 ; 95 \%$ confidence interval $(\mathrm{CI})=0.56-0.63]$ and at school after lunch $(\mathrm{AOR}=0.89 ; 95 \% \mathrm{CI}=0.83-0.94)$ and more likely to perceive their oral health to be poorer $(\mathrm{AOR}=1.63$, 95\% $\mathrm{CI}=1.54-1.72$ ) and experience oral symptoms (AOR= $1.75,95 \% \mathrm{CI}=1.65-1.86$ ) compared to usual Internet users.

\section{DISCUSSION}

Consistent with our hypothesis, we found that problematic Internet use was associated with less frequent toothbrush-

Table 1. Characteristics of the study population $(n=73238)$

\begin{tabular}{|c|c|c|c|}
\hline Variables & $\begin{array}{c}\text { Problematic Internet users } \\
\text { after adjustment*, } \%\end{array}$ & $\begin{array}{l}\text { Usual Internet users } \\
\text { after adjustment }{ }^{\dagger}, \%\end{array}$ & p-value \\
\hline Sex & & & $<0.001$ \\
\hline Male & 69.63 & 49.65 & \\
\hline Female & 30.37 & 50.35 & \\
\hline Grade & & & $<0.001$ \\
\hline Middle school 1st & 12.86 & 17.06 & \\
\hline Middle school 2nd & 16.95 & 16.56 & \\
\hline Middle school 3rd & 18.80 & 16.80 & \\
\hline High school 1st & 18.39 & 16.56 & \\
\hline High school 2nd & 16.43 & 16.52 & \\
\hline High school 3rd & 16.55 & 16.51 & \\
\hline Residential type & & & $<0.001$ \\
\hline With family & 94.43 & 95.73 & \\
\hline With a relative & 2.24 & 1.18 & \\
\hline With a friend/dormitory/alone & 2.22 & 2.56 & \\
\hline Facility & 1.12 & 0.53 & \\
\hline Alcohol use & & & $<0.001$ \\
\hline No & 40.42 & 46.12 & \\
\hline Yes & 59.58 & 53.88 & \\
\hline Smoking & & & $<0.001$ \\
\hline No & 65.35 & 75.60 & \\
\hline Yes & 34.65 & 24.40 & \\
\hline Substance use & & & $<0.001$ \\
\hline No & 98.27 & 99.49 & \\
\hline Yes & 1.73 & 0.51 & \\
\hline Perceived stress & & & $<0.001$ \\
\hline Very little to little & 9.62 & 16.76 & \\
\hline Average & 35.23 & 41.51 & \\
\hline Much to very much & 55.15 & 41.73 & \\
\hline
\end{tabular}

*sample size $=1$ 1644, weighted $=614492,{ }^{\dagger}$ sample size $=61594$, weighted $=3302749$ 
Table 2. Association between problematic Internet use and oral health behaviors and oral health status

\begin{tabular}{|c|c|c|c|c|}
\hline Dependent variable & $\begin{array}{c}\text { Problematic } \\
\text { Internet users after } \\
\text { adjustment*,\% }\end{array}$ & $\begin{array}{c}\text { Usual } \\
\text { Internet users after } \\
\text { adjustment }{ }^{\dagger}, \%\end{array}$ & OR $(95 \% \mathrm{Cl})$ & $\operatorname{AOR}(95 \% \mathrm{Cl})$ \\
\hline \multicolumn{5}{|l|}{ Toothbrushing frequency } \\
\hline Three or more times a day & 75.39 & 85.49 & $0.52(0.49-0.55)$ & $0.59(0.56-0.63)$ \\
\hline Twice a day or less & 24.61 & 14.51 & Ref & Ref \\
\hline \multicolumn{5}{|l|}{ Toothbrushing at school after lunch } \\
\hline Always or most & 35.73 & 41.74 & $0.78(0.72-0.83)$ & $0.89(0.83-0.94)$ \\
\hline Sometimes or never & 64.27 & 58.26 & Ref & Ref \\
\hline \multicolumn{5}{|c|}{ Dental check-up during the past 12 months } \\
\hline Yes & 62.90 & 65.24 & $0.90(0.86-0.95)$ & $0.98(0.93-1.03)$ \\
\hline No & 37.10 & 34.76 & Ref & Ref \\
\hline \multicolumn{5}{|l|}{ Self-perceived oral health } \\
\hline Unhealthy & 35.30 & 24.10 & $1.72(1.62-1.82)$ & $1.63(1.54-1.72)$ \\
\hline Fair to healthy & 64.70 & 75.90 & Ref & Ref \\
\hline \multicolumn{5}{|l|}{ Oral symptom experience } \\
\hline Yes & 75.90 & 63.93 & $1.78(1.67-1.89)$ & $1.75(1.65-1.86)$ \\
\hline No & 24.10 & 36.07 & Ref & Ref \\
\hline
\end{tabular}

AOR, adjusted for sex, school grade, residential type, alcohol, smoking, and substance use, and the level of perceived stress. Independent variable: problematic Internet use, dependent variable: oral health behaviors. *sample size $=11644$, weighted=614492, 'sample size $=61594$, weighted=3302749. AOR: adjusted odds ratio, $\mathrm{Cl}$ : confidence interval, OR: odds ratio

ing, poorer subjective oral health, and more objective oral symptoms. These associations remained significant even after controlling for possible confounders including sex, school grade, residential type, use of alcohol, tobacco, and substance, and the level of stress.

Consistent with our results, previous studies among adolescents and young adults found an association between problematic Internet use and bad personal hygiene, ${ }^{16,22)}$ although no study has investigated oral health hygiene specifically. There was no significant association between problematic Internet use and a visit to a dental clinic during the past 12 months in this study. On the contrary, Peltzer et al. ${ }^{14)}$ found a negative association between heavy Internet use and dental check-up at least once per year. This difference might have resulted from the fact that a visit to a dental clinic in the present study included both routine dental check-up and dental treatment. This may indicate that problematic Internet users might be less likely to visit a dental clinic for a routine checkup, but more likely to visit a dental clinic for oro-dental disease.

Extensive use of the Internet and computers may be associated with adverse oral health behaviors and poor oral health because it displaces time spent in personal hygiene care and medical care. In addition to these direct relationships between internet use and oral healthcare, adolescents with problematic Internet use could skip meals, have an unbalanced diet, and have insufficient sleep, ${ }^{7,14-16)}$ all of which might be associated with poor oral health. It should be noted that there might be third variables which simultaneously affect both problematic Internet use and poor oral health. For instance, stress and substance use have been found to be associated with problematic Internet use ${ }^{7,23)}$ as well as poor oral health. ${ }^{5,12)}$ However, the association between problematic Internet use and poor oral hygiene was significant even after adjustment for the level of stress and the use of alcohol, tobacco, and substance in the present study.

Oral health problems (e.g. dental caries) during adolescence could affect health-related quality of life (HRQOL). ${ }^{24,25)}$ Our findings suggested that problematic Internet use could lead not only to mental health problems but also to HRQOL in adolescent group. It is known that addictive behaviors are inversely associated with lower quality of life. ${ }^{26)}$ Our study expands a prior study showing that Internet addiction was linked to poor self-care, difficulty in performing daily routine, and lower HRQOL in adolescents and young adults. ${ }^{27}$

There are several limitations to this study. First, the crosssectional design did not allow us to reveal a temporal relationship between problematic Internet use and oral health behaviors and oral health status. Also, this study used self-reported questionnaires rather than objective examination or measurement, including information regarding oral health behaviors and oral health status. Third, we did not obtain information on dietary behavior such as use of a sugar product that may affect the association between problematic Internet use and poor oral health status. Finally, we did not evaluate accurate coexistent mental illness and substance use. Thus, further prospective studies using additional confounding 
variables and accurate comorbidity assessment are needed.

\section{CONCLUSION}

Despite these limitations, the findings indicate that problematic Internet use may adversely affect the oral health of Korean adolescents. Thus, oral health screening and Internetbased education are needed for adolescents with problematic Internet use. In particular, Internet-based information services or education may be a useful source of information on good oral health practices for this high-risk group.

\section{Acknowledgments}

This work was supported by a clinical research grant (No. 2017-04) from the National Center for Mental Health, Republic of Korea.

\section{Conflicts of Interest}

The authors have no financial conflicts of interest.

\section{REFERENCES}

1) Kebede B, Kemal T, Abera S. Oral health status of patients with mental disorders in southwest Ethiopia. PLoS One 2012;7:e39142.

2) Zucoloto ML, Maroco J, Campos JA. Impact of oral health on healthrelated quality of life: a cross-sectional study. BMC Oral Health 2016; 16:55.

3) Baker GH Jr. Integration of oral and general health in maternal and child populations. J Public Health Dent 1990;50:402-405.

4) Baker SR, Mat A, Robinson PG. What psychosocial factors influence adolescents' oral health? J Dent Res 2010;89:1230-1235.

5) Vasiliou A, Shankardass K, Nisenbaum R, Quiñonez C. Current stress and poor oral health. BMC Oral Health 2016;16:88.

6) He K, Kramer E, Houser RF, Chomitz VR, Hacker KA. Defining and understanding healthy lifestyles choices for adolescents. J Adolesc Health 2004;35:26-33.

7) Park S. Associations of physical activity with sleep satisfaction, perceived stress, and problematic Internet use in Korean adolescents. BMC Public Health 2014;14:1143.

8) Andrade MM, Benedito-Silva AA, Domenice S, Arnhold IJ, MennaBarreto L. Sleep characteristics of adolescents: a longitudinal study. J Adolesc Health 1993;14:401-406.

9) Serdula MK, Ivery D, Coates RJ, Freedman DS, Williamson DF, Byers T. Do obese children become obese adults? A review of the literature. Prev Med 1993;22:167-177.

10) Tezal M, Grossi SG, Ho AW, Genco RJ. The effect of alcohol consumption on periodontal disease. J Periodontol 2001;72:183-189.

11) Shizukuishi $S$, Hayashi N, Tamagawa H, Hanioka T, Maruyama S, Takeshita T, et al. Lifestyle and periodontal health status of Japanese factory workers. Ann Periodontol 1998;3:303-311.
12) Saini GK, Gupta ND, Prabhat KC. Drug addiction and periodontal diseases. J Indian Soc Periodontol 2013;17:587-591.

13) Shapira NA, Goldsmith TD, Keck PE Jr, Khosla UM, McElroy SL. Psychiatric features of individuals with problematic internet use. J Affect Disord 2000;57:267-272.

14) Peltzer K, Pengpid S, Apidechkul T. Heavy Internet use and its associations with health risk and health-promoting behaviours among Thai university students. Int J Adolesc Med Health 2014;26:187-194.

15) Matusitz J, McCormick J. Sedentarism: the effects of Internet use on human obesity in the United States. Soc Work Public Health 2012; 27:250-269.

16) Kim JH, Lau CH, Cheuk KK, Kan P, Hui HL, Griffiths SM. Brief report: predictors of heavy Internet use and associations with healthpromoting and health risk behaviors among Hong Kong university students. J Adolesc 2010;33:215-220.

17) Ha JH, Kim SY, Bae SC, Bae S, Kim H, Sim M, et al. Depression and Internet addiction in adolescents. Psychopathology 2007;40:424-430.

18) Jang KS, Hwang SY, Choi JY. Internet addiction and psychiatric symptoms among Korean adolescents. J Sch Health 2008;78:165171.

19) Park S, Hong KE, Park EJ, Ha KS, Yoo HJ. The association between problematic internet use and depression, suicidal ideation and bipolar disorder symptoms in Korean adolescents. Aust N Z J Psychiatry 2013;47:153-159.

20) Korea Centers for Disease Control and Prevention. Korea youth risk behavior web-based survey: survey summaries. Cheongwon: Korea Centers for Disease Control and Prevention;2010.

21) Kim K, Ryu E, Chon MY, Yeun EJ, Choi SY, Seo JS, et al. Internet addiction in Korean adolescents and its relation to depression and suicidal ideation: a questionnaire survey. Int J Nurs Stud 2006;43:185192.

22) Kamal NN, Mosallem FA. Determinants of problematic Internet use among el-minia high school students, Egypt. Int J Prev Med 2013;4: 1429-1437.

23) Lee YS, Han DH, Kim SM, Renshaw PF. Substance abuse precedes Internet addiction. Addict Behav 2013;38:2022-2025.

24) Bastos RS, Carvalho ES, Xavier A, Caldana ML, Bastos JR, Lauris JR. Dental caries related to quality of life in two Brazilian adolescent groups: a cross-sectional randomised study. Int Dent J 2012; 62:137-143.

25) Peres KG, Peres MA, Araujo CL, Menezes AM, Hallal PC. Social and dental status along the life course and oral health impacts in adolescents: a population-based birth cohort. Health Qual Life Outcomes 2009;7:95.

26) Lincoln A, Paasche-Orlow MK, Cheng DM, Lloyd-Travaglini C, Caruso C, Saitz R, et al. Impact of health literacy on depressive symptoms and mental health-related: quality of life among adults with addiction. J Gen Intern Med 2006;21:818-822.

27) Tran BX, Huong LT, Hinh ND, Nguyen LH, Le BN, Nong VM, et al. A study on the influence of internet addiction and online interpersonal influences on health-related quality of life in young Vietnamese. BMC Public Health 2017;17:138. 